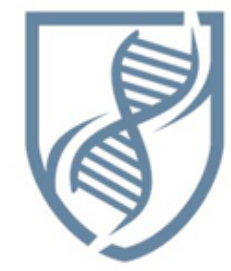

Journal of Bioscience and Applied Research
JBAAR

WWW.JBAAR.ORG

\title{
Effects of swine flu (H1N1) vaccine on albino rats
}

\author{
Fatma Ahmed Eid ${ }^{1}$, Aly Fahmy Mohamed ${ }^{2}$, Alya Mohammed Aly ${ }^{1}$ and Nadia Fathy Ibrahim ${ }^{1}$ \\ 1. Department of Zoology, Faculty of Science, Al- Azhar University, Cairo, Egypt. \\ 2.The Holding Company for Biological Products and Vaccines (EGYVAC-VACSERA), Dokki, Giza, Egypt. \\ Corresponding author email: fatmaeid22@yahoo.com
}

\begin{abstract}
The pandemic flu (2009) is a global outbreak of a new strain of H1N1 influenza virus that referred as "swine flu". The 2009 flu pandemic vaccines (H1N1 vaccines) are the biological preparation of influenza vaccines that have been developed to protect and improve immunity against the pandemic H1N1/09 virus. Squalene has been added to vaccine as immunologic adjuvant to stimulate the immune system, increase the response to the vaccine and reduce amount of usage vaccine. Thimerosal has been added to some vaccines as a preservative because it is effective in preventing bacterial contamination, particularly in multidose containers. To investigate the possible immunological effects of swine flu vaccine, Albino rats were injected with $\mathrm{H} 1 \mathrm{~N} 1$ antigen contained thimerosal, adjuvant and H1N1 vaccine. Results obtained in the present study showed that squalene and thimerosal contributed to the regiment of adverse reactions and symptoms, which act as detergents instead of its helper role of vaccine that undergone toxicity effectors in the biological pathways including; immunopathological and histopathological effects; the damage was done by vaccine, particularly when potentiated by powerful "immunoenhancers" caused a strong immunostimulation that emphasized by results of this research as well as its biological hazards which are more pronounced when act together as whole vaccine than they act individually so the adverse events that resulted from treatment with squalene-adjuvanted vaccine are more potent than those of either antigen or squalene- treated groups.
\end{abstract}

Keywords:H1N1; Squalene; Vaccine.

\section{Introduction}

Virus spreads all over the world in seasonal epidemics resulting in severe illness to million of cases yearly and deaths as well (WHO, 2009b). A novel strain of H1N1 resulted when a triple reassortment of bird, pig and human flu viruses combined with a Eurasian pig flu virus (Trifonov et al., 2009). H1N1 flu virus cannot be spread by eating pork (Huffstutter, 2009) or pork products (CDC, 2010). This new virus subtype is efficiently able to be transmitted from human to human which has led to increase the numbers of patients that cause pandemic influenza (Gangurde et al., 2011). Influenza virus infection, one of the most common infectious diseases, is a highly contagious airborne disease that causes an acute febrile illness and results in variable degrees of systemic symptoms, ranging from mild fatigue to respiratory failure and death. These symptoms contribute to significant loss of workdays, human suffering, mortality and significant morbidity (Islam and Rahman, 2010). The 2009 flu pandemic vaccines developed to protect against the pandemic H1N1virus. These vaccines either contain inactivated (killed) influenza virus, or weakened live virus that cannot cause influenza. The killed vaccine is injected, while the live vaccine is given as a nasal spray (MariePaule, 2009). Vaccines often contain other substances, for example, vaccines may contain adjuvants that enhance antigen-specific immune responses (e.g., squalene); preservatives that prevent bacterial or fungal contamination (eg, thimerosal), Pandemic-influenza vaccines containing split-inactivated-virus antigen have been formulated with the immunostimulatory adjuvant system AS03 to enhance the antigen immunogenicity and reduce antigen content per dose, the administration of repeated doses of the AS03 
vaccine was primarily associated with transient mild inflammation at the injection site and draining lymph nodes. The biodistribution kinetics of AS03 constituents were consistent with AS03 inducing this pattern of inflammation (Segal et al., 2015). Adjuvants are often included in vaccines to enhance the recipient's immune response to a supplied antigen while keeping the injected foreign material at a minimum dose (David and Andrew, 2009). According to Asa et al. (2000) the damage is done by vaccines, particularly when potentiated by powerful "immunoenhancers" such as squalene. glucopyranosyl lipid adjuvant (GLA) is a potent Th1-response-inducing adjuvant when formulated in a squalene oil-in-water emulsion (Anthony et al., 2015). The pathologic reaction to the adjuvants starts at the injection site with mild erythema, muscles aches and swelling (Ho, 2009a), followed by tissue necrosis, intense inflammation and granulomatous lesion (Viera, 2001). Adjuvants can break tolerance meaning and they can disable the immune system to the degree that it loses its ability to distinguish what is 'self' from what is foreign. Normally, the immune system ignores the constituents of one's own body. Immunologists call this tolerance; but if something happens to break tolerance, then the immune system turns relentlessly self-destructive and attacking the body it is supposed to defend (Jeff, 2015).Administration of vaccine was contributed to the Guillain-Barre syndrome (Roan, 2009). A small number of death was recorded shortly after the administration of the H1N1 vaccine (WHO, 2009a). In Canada there had been 24 confirmed cases of anaphylactic shock following vaccination, including one death (Smith, 2009). There is a scientific evidence that the swine flu vaccine, especially the squalene as adjuvant, caused serious injury and death. Barbro et al. (2000) reported that a single injection of the adjuvant squalene into rats triggered "chronic, immunemediated joint-specific inflammation" also known as rheumatoid arthritis. When thimerosal is degraded or metabolized, one product (ethyl mercury) is formed, an organic derivative of mercury (NIAID, 2009). Otherwise Sanfeliu et al. (2001) demonstrated that methylmercury toxicity in neurons implicated to reactive oxygen species (ROS) and depletion of intracellular glutathione as major contributors to mercury-induced cytotoxicity. In addition the neurotoxicity of methyl mercury has been relatively well studied (James et al., 2005). The use of thimerosal can cause autism and other developmental disorders (Burton, 2003). Due to many pathologic changes that occurred after exposure to H1N1 vaccine, the present study was planned to determine the immune response and the histopathological changes in the splenic tissue of Albino rats after $\mathrm{H} 1 \mathrm{~N} 1$ vaccine injection.

\section{Materials and Methods}

\section{Experimental animals}

Albino rats weighing 65-70 gm were obtained from The Nile Company for Pharmaceutical and Chemical Industries. After an acclimatization period of one week, the animals were divided into four groups (20 mice /group) and housed in wire bottomed cages in a room under standard conditions of illumination with a 12-hours light-dark cycle at $25 \pm 1^{\circ} \mathrm{C}$. They were provided with water and a balanced diet. All animals received care in compliance with the Egyptian rules for animal protection.

\section{Experimental protocol}

Animals were divided into different treatment groups as follows: the first group (Con), the second group received intramuscular injection of $\mathrm{H} 1 \mathrm{~N} 1$ vaccine suspension (antigen that contained thimerosal- (Thio- Ag)) at the zero day, and the 21st day, the third group received intramuscular injection of Adjuvant (Adj; AS03) at the zero day, and the 21st day, the fourth group received a intramuscular injection of whole $\mathrm{H} 1 \mathrm{~N} 1$ vaccine (mixture of antigen and adjuvant- Mix) at the zero day, and the 21st day. Animals of all the treated groups vaccinated with 0.5 $\mathrm{ml}$, the same dose of a human multiplied by conversation factor (0.018)/200 gm of body weight of rat according to Paget and Barnes (1964), in which each rat received 1.51 of treatment dissolved in 498.51 saline, the doses were prepared for 10 rats at each time. Animals of all groups; Con, Thio- Ag, Adj and Mix were decapitated after 21 and 42 days post-treatment $(n=5)$. The spleens of rats were carefully removed and prepared to use for the various immunological and histopathological determinations.

\section{Immunological Studies}

Proliferation Assay:

Twenty-one days post vaccination, spleen tissues were dissected from Con, Thio- Ag and Mix groups. Splenocytes prepared for in- vitro stimulation assay with phytoheamagglutinine and $\mathrm{H} 1 \mathrm{~N} 1$ vaccine according to Forrest et al. (1996).

\section{Cytokine Assays:}

Supernatants were derived from the cultures of splenic lymphocytes. Briefly, supernatants were harvested after 24 $\mathrm{h}, 48 \mathrm{~h}, 96 \mathrm{~h}$ and $120 \mathrm{~h}$, and assayed for the presence of IFN- $\gamma$ according to Kelder and Rashidbaigi (1986), IL-10 according to Everson (2005) and TNF- $\alpha$ according to Brouckaert (1993) using a sandwich enzyme-linked immunosorbent assay (ELISA). The resulting optical density was read on a microtitre plate reader (ELX-808, BioTek Instruments, Winooski, VT, USA) with $450 \mathrm{~nm}$ wavelength correction.

\section{Interferon Gamma (Rat-IFN- $\gamma$ ) ELISA Kit:}

Supernatant IFN- $\gamma$ was determined using rat interferon gamma (Rat-IFN- $\gamma$ ) ELISA (Enzyme-Linked Immunosorbent Assay) kit; it is an in vitro enzyme-linked immunosorbent assay for the quantitative measurement of Rat IFN- $\gamma$ ) cell lysate and tissue lysate method, PBL, Immuno Biological Laboratories). (Code no. 43500-1, v.1.3).

\section{Interlukin-10 (Rat- IL-10) ELISA Kit:}

Supernatant IL- 10 was determined using Rat IL-10 ELSA (Enzyme-Linked Immunosorbent Assay) kit; it is an in vitro enzyme-linked immunosorbent assay for the quantitative measurement of Rat IL-10 cell lysate and tissue lysate method, RayBio. (Cat. N.: ELR-IL10-001C). 


\section{Rat TNF-alpha ELISA Kit:}

Supernatant TNF-alpha was determined using rat TNFalpha ELSA (Enzyme-Linked Immunosorbent Assay) kit; it is an in vitro enzyme-linked immunosorbent assay for the quantitative measurement of Rat IL-10 cell lysate and tissue lysate method, RayBio. (Cat. N.: ELR-TNFalpha001C).

\section{Statistical analysis}

Results were expressed as the mean \pm standard error of the mean (SEM). Data for multiple variable comparisons were analyzed by one-way analysis of variance (ANOVA). For the comparison of significance between groups, Duncan's test was used as a post hoc test according to the statistical package program (SPSS version 17.0)

\section{Histological study}

Spleens of vaccinated rats were washed in saline and fixed in $10 \%$ neutral formalin, embedded in paraffin, sectioned at $5 \mathrm{~m}$ and stained with haematoxylin and eosin stain according to the method of Drury and Wallington (1980), Mallory's trichrome stain, periodic acid Schiff technique (Pearse, 1977) and mercuric bromophenol blue (Mazia et al., 1953) for light microscopic observations.

\section{Results}

\section{Immunological Results: Interferon - gamma $($ INF - $\gamma)$ :-}

Figure 1 summarizes the effect of vaccination of thiomersal- containing antigen and mixture of vaccine ingredients was given for 21 days, in addition to in-vitro stimulation with phytoheamagglutinine and H1N1vaccine was given for 24, 48, 96 and 120 hours post-stimulation were produced disturbances in interferon- gamma level. In view of the present results, stimulation of splenic cells invitro with phytoheamagglutinine exhibited a non significant $(\mathrm{p}<0.05)$ increase in the INF $-\gamma$ compared to the control group after 24 and 48 hours post-stimulation, however it exhibited a significant increase after 96 and 120 hours poststimulation.At the same time a significant increase $(\mathrm{p}<0.05)$ in INF $-\gamma$ was observed in flu vaccine $(\mathrm{H} 1 \mathrm{~N} 1)$ in-vitro stimulated cells all over the experimental periods.The splenic cells of squalene- non adjuvanted flu vaccine and squalene- adjuvanted flu vaccine groups induced a significant increase $(p<0.05)$ in the INF $-\gamma$ compared to the control group after 24, 48, 96 and 120 hours poststimulation. But the splenic cells of both groups when stimulated in-vitro with phytoheamagglutinine showed a significant increase compared to the control group, after 24 , 48, 96 and 120 hours post-stimulation. A significant increase in the INF $-\gamma$ was observed after in vitro stimulation all over the experimental periods. The INF $-\gamma$ level was elevated respectively in these groups as the following: squalene- non adjuvanted flu vaccine then squalene- adjuvanted flu vaccine.

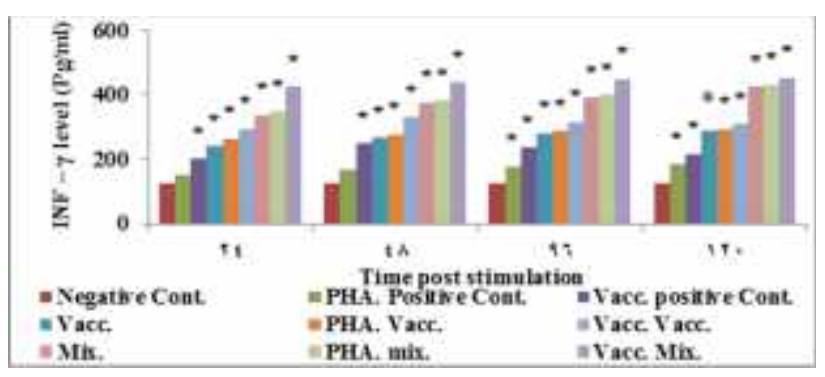

Figure 1: Comparative evaluation of interleukin-10 level realized from spleenic cells of non immunized control, squalene- non adjuvanted flu vaccine and squalene- adjuvanted flu vaccine groups to phytoheamagglutinine and flu vaccine (H1N1) stimulated cells. vaccine.*, significant change at $\mathrm{p}<0.05$ with respect to Con group.

Interleukin- 10 (IL- 10):-

As shown in Figure 2, vaccination of thiomersalcontaining antigen and mixture of vaccine ingredients on given for 21 days, in addition to in-vitro stimulation with phytoheamagglutinine and $\mathrm{H} 1 \mathrm{~N} 1$ vaccine at 24 , 48, 96 and 120 hours post-stimulation were produced elevation in interleukin- 10 level. Stimulation of splenic cells in-vitro with phytoheamagglutinine exhibited a non significant increase in the IL- 10 compared to the control group after 24 hours post-stimulation, but they exhibited a significant increase after 48, 96 and 120 hours post-stimulation, on the other hand a significant increase $(p<0.05)$ in IL- 10 was observed in flu vaccine (H1N1) in-vitro stimulated cells after 24, 48, 96 and 120 hours of stimulation. The splenic cells of squalenenon adjuvanted flu vaccine squalene- adjuvanted flu vaccine groups induced a significant increase $(\mathrm{p}<0.05)$ in the IL- 10 compared to the control group after24, 48, 96 and 120 hours post-stimulation respectively. At the same time the splenic cells of these groups when stimulated in-vitro either with phytoheamagglutinine or flu vaccine, they showed a significant increase in the IL- 10 compared to the control group. The IL- 10 percentage in these groups recorded higher values than that of non immunized control group. Deposit the fact that it recorded higher values in squalene- non adjuvanted flu vaccine group than squalene- adjuvanted flu vaccine group.

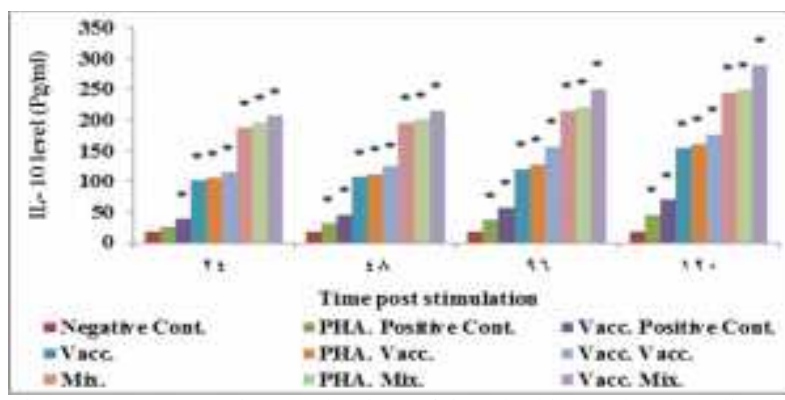

Figure 2: Comparative evaluation of interleukin-10 level realized from spleenic cells of non immunized control, squalene- non adjuvanted flu vaccine and squalene- adjuvanted flu vaccine groups to phytoheamagglutinine and flu vaccine $(\mathrm{H} 1 \mathrm{~N} 1)$ stimulated cells. vaccine.*, significant change at $\mathrm{p}<0.05$ with respect to Con group. 


\section{Tumor necrosis factor (TNF)- $\alpha$ :-}

In Figure (3) a significant increase $(\mathrm{p}<0.05)$ in TNF $-\alpha$ was observed in phytoheamagglutinine and flu vaccine (H1N1) in-vitro stimulated splenic cells after 24, 48, 96 and 120 hours of stimulation.

The splenic cells of squalene- non adjuvanted flu vaccine group and squalene- adjuvanted flu vaccine group induced a significant increase $(p<0.05)$ in the TNF $-\alpha$ compared to the control group. Although, in-vitro stimulation of the splenic cells of these two groups with phytoheamagglutinine or with flu vaccine showed a significant increase in the TNF - $\alpha$ compared to the control group.

The TNF $-\alpha$ percentage was elevated respectively as the following: non stimulated flu vaccine groups then phytoheamagglutinine stimulated groups and finally flu vaccine stimulated groups. While squalene- adjuvanted flu vaccine group recorded higher values than those of squalene- adjuvanted flu vaccine group according to the previous degradation.

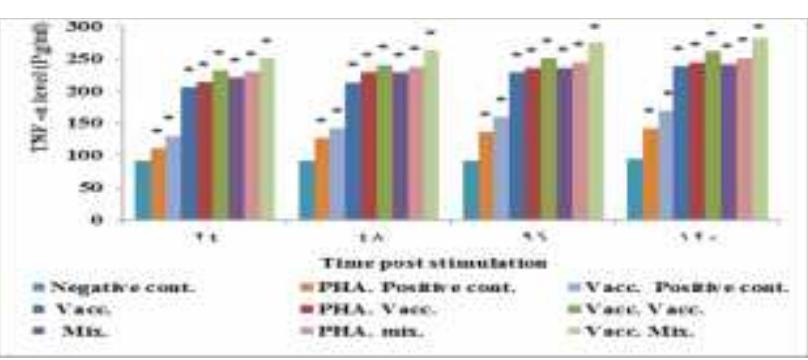

Figure 3: Comparative evaluation of tumor necrosis factor (TNF) $-\alpha$ level realized from spleenic cells of non immunized control, squalene- non adjuvanted flu vaccine and squalene- adjuvanted flu vaccine groups to phytoheamagglutinine and flu vaccine $(\mathrm{H} 1 \mathrm{~N})$ stimulated cells. vaccine.*, significant change at $\mathrm{p}<0.05$ with respect to Con group.

The histopathological observations:

The histological alterations are shown in Figures 4-7.

\section{Discussion}

\section{Immunological Changes:}

\section{1- Interferon-gamma (IFN- $\gamma)$ :-}

The results of the current experiment showed non significantly increased differences in values of IFN$\gamma$ produced by phytohaemagglutinin (PHA)-stimulated splenocytes of non immunized control group at 24 and 48 hours post-stimulation, but exhibited significant increased differences at 96 and 120 hours post-stimulation compared with negative control group. These results are in line with those of Picker $e t$ al. (1995). PHA produces a wide range of both Th1 and Th2 cytokines, e.g., for TNF- $\alpha$, IFN- $\gamma$ and IL10 (Kowalczyk et al., 1997).

The present experiment showed significant increased differences in values of IFN- $\gamma$ produced by phytohaemagglutinin (PHA) - stimulated splenocytes of all the treated groups at different intervals $(24,48,96$ and 120 hours post-stimulation), this is may be due to immunostimulation action of (PHA) and vaccine components. These results are in line with those of Chopra et al. (1997) who stated that the splenic cells were stimulated in vitro with phytohaemagglutinin (PHA), were able to induce the release of interferon-gamma (IFNgamma) which was found to increase with time and it reached its peak values on the seventh day after stimulation. Influenza vaccine has been shown to contribute to proliferation of IFN- $\gamma$ production and a cytolytic response after vaccination (Monteiro et al., 1998). Therefore, the high concentrations of IFN- $\gamma$ cytokines suggest that vaccine was probably more effective in stimulation of naive CD8 cells and thus a cytotoxic response than influenza infection (Huckriede et al., 2005).

The present study showed significantly increased differences in values of IFN- $\gamma$ produced by flu vaccine (H1N1) -stimulated splenocytes than those produced by phytohaemagglutinin (PHA) -stimulated splenocytes of non immunized control group and squalene non adjuvanted flu vaccine (H1N1) immunized group. These results are in line with those of Diaz-Sanchez et al. (1993) who stated that IFN-gamma production by phytohaemagglutinin (PHA) stimulated splenocytes or purified splenic $\mathrm{T}$ cells was substantially reduced as compared with animals which were given antigen.

In the present study elevation of IFN- $\gamma$ values of flu vaccine (H1N1) -stimulated splenocytes of non immunized control group and squalene- non adjuvanted flu vaccine (H1N1) immunized group were observed 24 and 48 hours post-stimulation then declined after this at 96 and 120 hours post-stimulation, this may be due to immunosuppression action of thimerosal. This investigation is in agreement with those of Vetvicka and Vetvickova (2009) who reported that the elevation of IFN-g declined due to suppression of both cellular and humoral responses but a significant increase was seen again after 14 days of treatment and they added that this is may be due to the organic mercurials that are directly responsible for the immunosuppressive effect and it is contribute to the autoimmune reaction and also this is due to the rapid transformation of ethyl $\mathrm{Hg}$ and methyl $\mathrm{Hg}$ in the body to inorganic $\mathrm{Hg}$ (mercuric mercury), which reached a maximum after 14 days thimerosal treatment.

The present study showed significant increased values of IFN- $\gamma$ produced by flu vaccine $(\mathrm{H} 1 \mathrm{~N} 1)$-stimulated splenocytes of squalene- adjuvanted flu vaccine (H1N1) immunized group at different intervals. The elevation of IFN- $\gamma$ recorded in the present work agrees with the results of Szyszko et al. (2006) who emphasized that the virus vaccine induced a significantly higher IFN- $\gamma$ after the first and the second vaccinations in mice.

All of these findings may be due to combined action of inactivated virus, thimerosal and squalene as adjuvant, this investigation in agreement with those of Szyszko et al. (2006) who had shown that inactivated virus when added to vaccine it causes immunostimulation effect.

As well as the adjuvant causes immune-stimulating complexes (ISCOMs1) (Gomez-Vargas et al., 2004). 


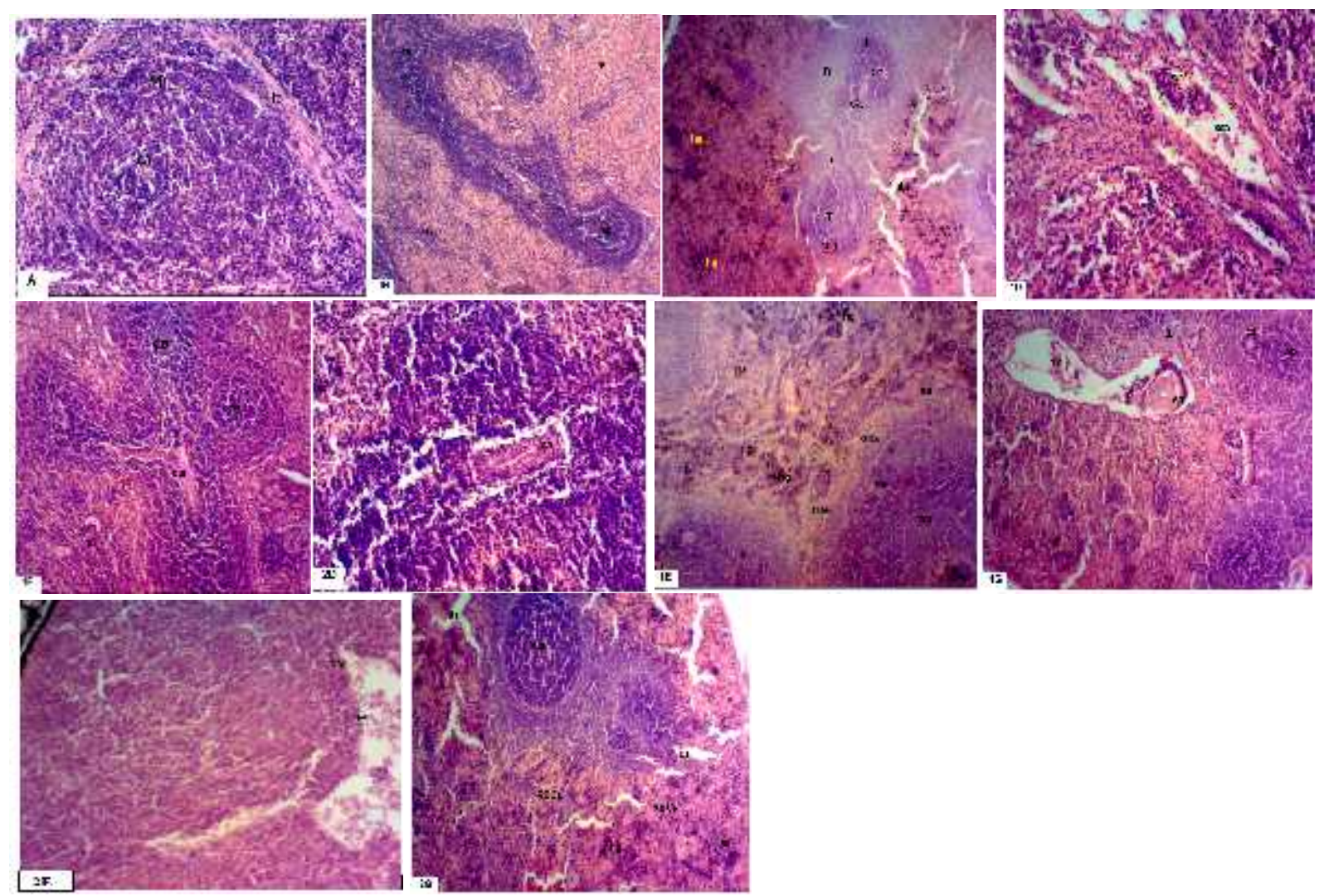

Figure 4: (A) Normal histological features of splenic tissue of the control group stained with hematoxylin and eosin, it consists of the capsule, white pulps (wp) with the central arteries (ca), trabeculea (tb) and red pulps (rp), vascular organization and cellular composition (100X). (B) Sections of thiomersal- containning antigen exposed spleen after the 1st dose showed increased number of connected white pulps (wp), increased proliferation of lymphocytes in them, normal central artery and red pulps (rp) with dilated and elongated trabecular vein (tv) (50X). (C) thiomersal- containning antigen exposed spleen after the 2 nd dose showed poorly stained lymphocytes (L) and walls of central arteries (ca) of the white pulps (wp). Numerous haemosidrin granules (hg) in the red pulps (rp) and some degenerated areas (da) (50X). (D) Sections of adjuvant treated spleen tissue after the 1st dose showed loss of normal architecture of the splenic tissue with highly disturbed white pulps (wp), thickened trabeculea (tb) with highly dilated and elongated trabecular vein (tv) which contained haemolysed RBCs and lots of WBCs. Notice: Highly thickened wall of the central artery with narrow lumen (ca) (50X). (E) Sections of adjuvant treated spleen tissue after the 2nd dose showed numerous necrotic areas (na), distorted white pulps (wp), destructed walls ofthe central arteries(ca), numerous haemosidrin granules (hg) and pools of haemolyzed RBCs andhighly widened and elongated trabecular vein (tv) with ruptured endothelial lining (e) of it. It contained haemolyzed RBCs (1E X50; 2E X100). (F) Sections of H1N1 vaccine exposed spleen after the 1st dose showed increased proliferation of the adjacent white pulps (wp) with highly elongated, branched and thickened walls of the central arteries (ca),normal red pulps (rp) and highly dilated trabecular vein (tv) which contains haemolyzed WBCs and RBCs ( $50 \mathrm{X}$ ). (G) Sections of H1N1 vaccine exposed spleen after the 2nd dose showed highly thickened walls of splenic arteries (sa), splenic veins (sv), destructed walls of the central arteries (ca) bizarre structure and distribution of the white pulps (wp), while others appeared somewhat normal, thickened trabecular walls (tb), numerous degenerated areas (da), pools of degenerated RBCswith numerous haemosidrin granules (hg) (50X). 


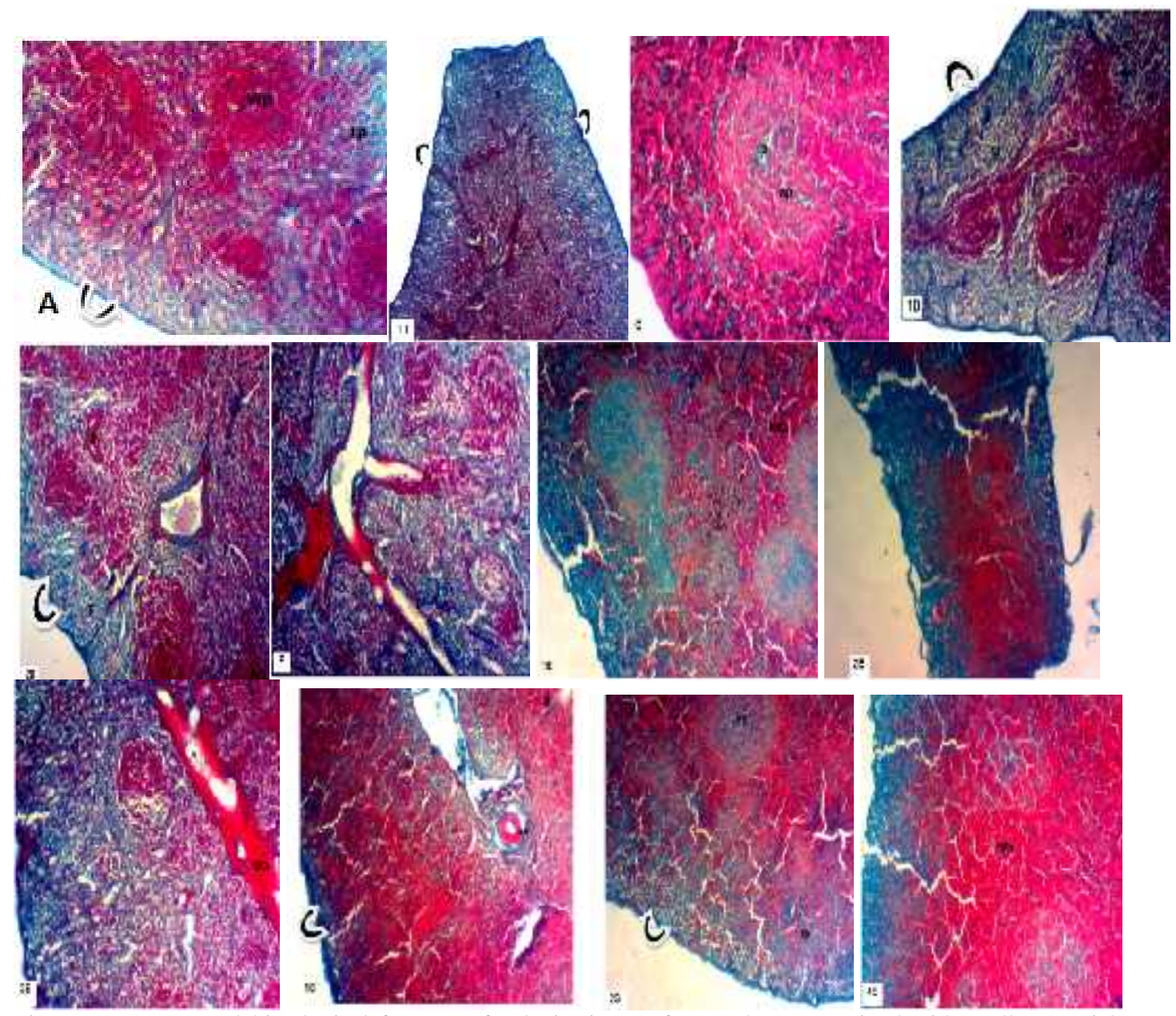

Figure 5: (A) Normal histological features of splenic tissue of control group stained with Mallory's trichrome stain showed thin collagen bundles supporting the capsule (B) red pulps (Rp) and white pulps (wp). (B) Sections of thiomersalcontainning antigen exposed spleen after the 1st dose showed highly increased collagen bundles in the thickened capsule ( ), trabeculea (tb), walls of blood vessels (bv),red (rp) and white (wp) pulps. (C) thiomersal- containning antigen exposed spleen after the 2nd dose) showed increased collagen fibers in the red (rp) and white (wp) pulps especially in and around the wall of the central arteries (ca). (D) Sections of adjuvant treated spleen tissue after the 1st dose showed increased collagen bundles especially under the capsule ) and trabecule (tb), wall of blood vessels (bv), and through red (rp) and white pulps (wp). (E) Sections of adjuvant treated spleen tissue after the 2nd dose and (F) Sections of H1N1 vaccine exposed spleen after the 1st dose showed highly increased collagen bundles in the splenic tissue and brightly stained pools of RBCs. (G) Sections of H1N1 vaccine exposed spleen after the 2nd dose showed increased collagen bundles in the splenic tissue especially around the splenic artery (sa), in and under the capsule ( $)$ and in the red (rp) and white (wp) pulps. (50X). 


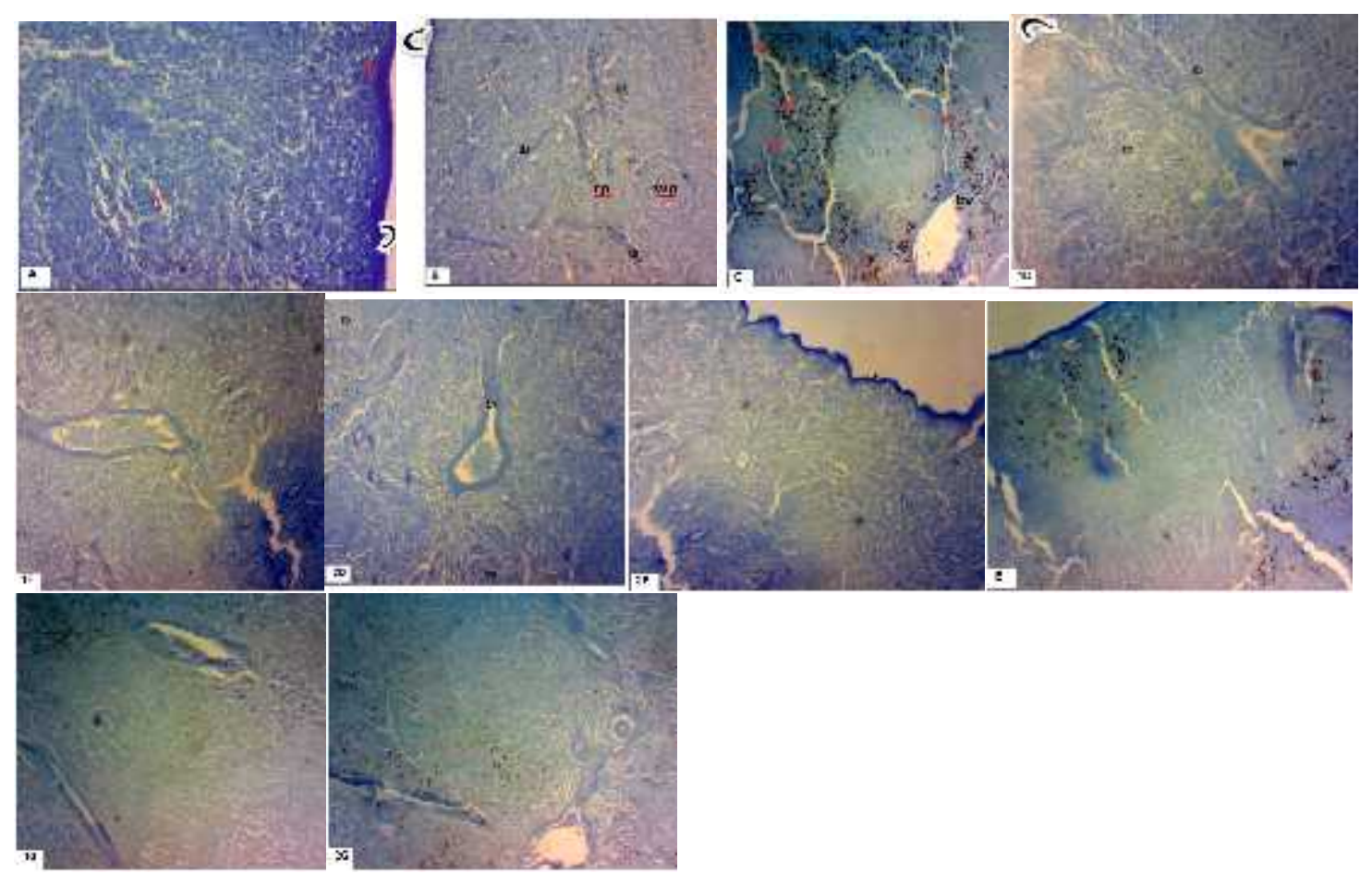

Figure 6: (A) Normal histological features of splenic tissue of control group showed normal distribution of total protein in the splenic tissue. Notice: deeply stained capsule $\quad$ ( ) trabeculea (tb) and wall of the central arteries (ca) (100X). (B) Sections of thiomersal- containning antigen exposed spleen after tie 1st dose showed poorly stained trabeculea (tb), red (rp) and white (wp) pulps with moderately stained capsule ( O . (C) thiomersal- containning antigen exposed spleen after the 2nd dose showed highly decreased total protein in the splenic tissue with negatively stained degenerated areas (da). Notice: deeply stained haemosidrin granules (hg) in the red pulps (rp) and moderately stained walls of the blood vessels (bv). (D) Sections of adjuvant treated spleen tissue after the 1st dose) showed reduced stain affinity in and under the capsule ( moderately stained trabeculea (tb) and walls of the blood vessels (bv). Reduced stan affinity of total protein was detected in (E) Sections of adjuvant treated spleen tissue after the 2nd dose, (F) Sections of H1N1 vaccine exposed spleen after the 1st dose. And (G) Sections of H1N1 vaccine exposed spleen after the 2nd dose. Notice: walls of the blood vessels were moderately stained. (50X). 


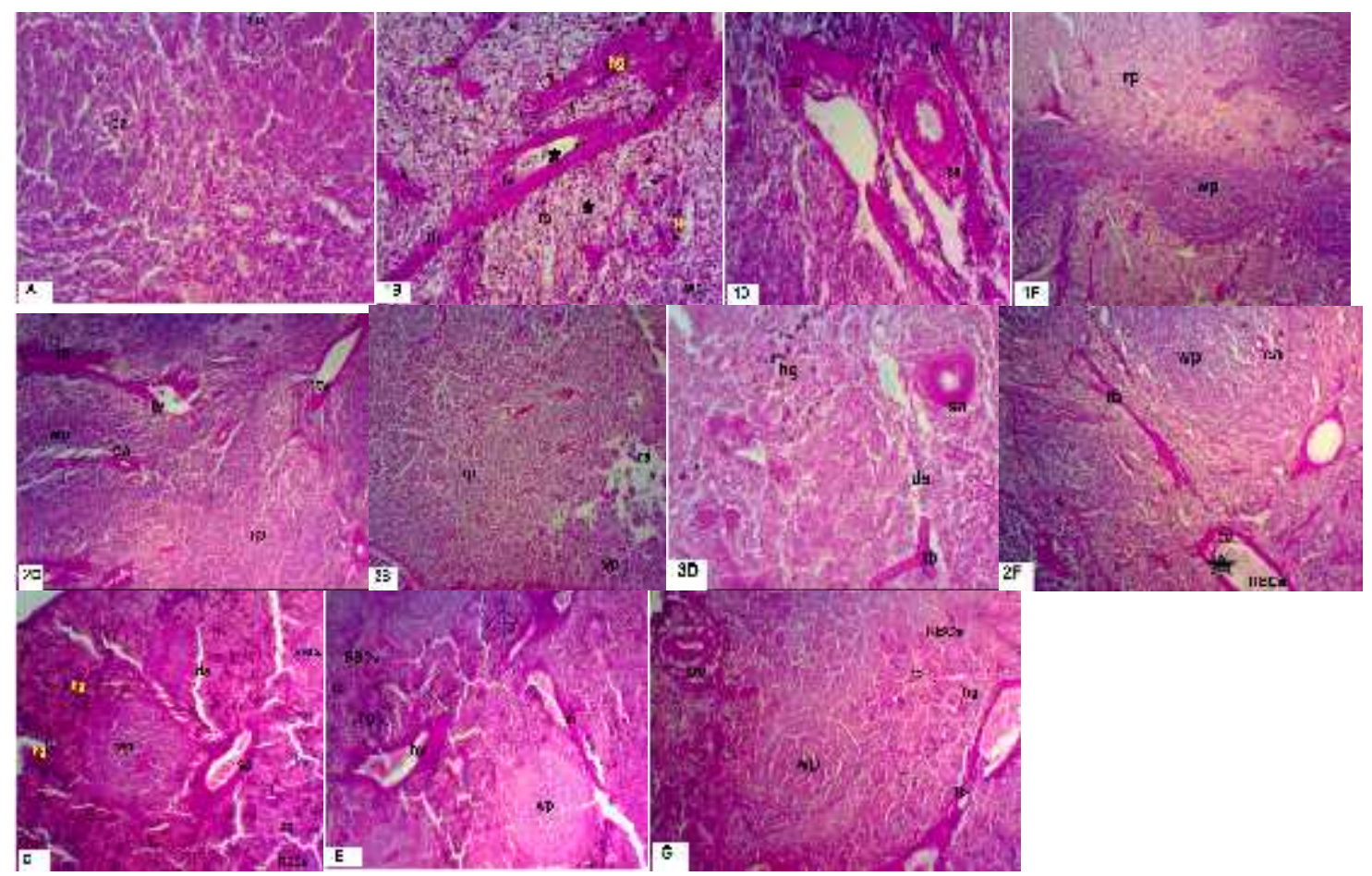

Figure 7: (A) Normal histological features of splenic tissue of control group showed normal distribution of PAS positive materials in the splenic tissue. Notice: deeply stained walls of the central arteries (ca) (100X). (B) Sections of thiomersal- containning antigen exposed spleen after the 1st dose showed highly thickened and deeply stained trabeculea (tb), numerous haemosidrin granules (hg), depleted RBCs and WBCs ( $)$ insid the trabecular vein (tv) and in the red (rp) \& white pulps (wp). Degenerated areas (da) are negatively stained (50X). (C) thiomersal- containning antigen exposed spleen after the 2nd dose showed the red pulps (rp) containing homogenous red color indicating haemolysed RBCs and numerous haemosidrin granules (hg). Notice: haemolyzed blood cells inside the artery (sa) and the white pulps (wp) which showed diffused stain affinity and the negatively stained degenerated areas (da) (50X). (D) Sections of adjuvant treated spleen tissue after the 1st dose showed deeply stained walls of the splenic vein (sv), artery (sa), trabeculea (tb) and walls of trabecular veins (tv), central arteries (ca) with reduced stain affinity in red (rp) and white pulps (wp) and negatively stained degenerated areas (da) with lots of haemosidrin granules (hg) (1DPAS X 100 and 2D,3D PAS X 50). (E) Sections of adjuvant treated spleen tissue after the 2nd dose showed faintly stained PAS +ve materials in the white pulps (wp) and numerous haemosidrin granules (hg) in the red pulps (rp) and insid the blood vessels (bv). Notice: Highly thickened and deeply stained trabeculea (tb) (50X). (F) Sections of H1N1 vaccine exposed spleen after the 1st dose showed normal stain affinity of PAS +ve materials in some white pulps (wp), while highly decreased stain affinity was detected in the red pulps (rp) and the remnant of white pulps. Walls of the trabeculea (tb) and thickened central artery (ca) showed dense stain affinity, while haemolysed blood cells ( inside the highly dilated trabecular vein (tv) are poorly stained (50X). (G) Sections of H1N1 vaccine exposed spleen after the 2nd dose showed somewhat normal stain affinity of PAS + ve materials in the white pulps (wp), but haemolysed RBCs in the red pulps (rp) acquired diffused red color and numerous haemosidrin granules (hg). Highly thickened walls of the blood vessels (bv) and trabeculea (tb) acquired deep red coloration (50X). 


\section{2- interleukin10 (IL-10):-}

In the present study values of IL-10 produced by phytohaemagglutinin (PHA) -stimulated splenocytes of non immunized control group showed a non significant increased difference after 24 hour stimulation, while they showed significant increased differences at different intervals (48, 96 and 120 hours post-stimulation). These results are supported by those of Carter and Swain (1997) who stated that stimulation for $24 \mathrm{~h}$ with PHA induced a non significant increase in the frequency of IL-10-producing cells. While a significant increase of IL-10 expression was detected at 48 h PHA stimulation (Jarołsaw et al., 2001).

The results of current study showed elevation of IL-10 values that produced by phytohaemagglutinin (PHA) stimulated splenocytes of all the treated groups at different intervals (24, 48, 96 and 120 hours post-stimulation). These results are in the same line with those of Ahmed and Yehia (2007) who found that the interleukin-10 (IL-10) in the splenocytes cultures was pulsed with phytohaemagglutinin (PHA) stimulation.

In the recent study the elevation of IL-10 values of flu vaccine (H1N1) -stimulated splenocytes of non immunized control group and squalene non adjuvanted flu vaccine (H1N1) immunized group were observed at different intervals $(24,48,96$ and 120 hours post-stimulation), this may be due to presence of thimerosal. This investigation is supported by Anshu et al. (2007) who documented that the thimerosal induced increased $\mathrm{TH} 2$ and may result in abnormal immunologic responses, including allergy and autoimmunity. Otherwise, the elevation of IL-10 produced by $(\mathrm{H} 1 \mathrm{~N} 1)$ vaccine in the present study may be due to addition of inactivated virus to the vaccine this notification come as same line with those of Szyszko et al. (2006) who reported that the studies in animals and humans had shown that addition of small amounts virus to the subunit vaccine had a potentiating effect on the humoral immune response. The present study showed a significant increase in values of IL-10 produced by flu vaccine (H1N1) -stimulated splenocytes of squalene- adjuvanted flu vaccine (H1N1) immunized group at different time intervals. These results are in agreement with those of Szyszko et al. (2006) who reported that influenza vaccine induced a strong mixed cytokine response particularly in induction of Th2 of cytokines especially after the second dose and substantially influences the magnitude and quality of the immune response. The cytokines profile in stimulated splenocytes was investigated as IL-10 to the type 2 response.

Squalene mediated Th2 antibody responses (Baudner et al., 2009), because it successfully augment influenza vaccines (Dormitzer et al., 2011). In the current study the value of IL-10 produced by flu vaccine $(\mathrm{H} 1 \mathrm{~N} 1)$-stimulated splenocytes of squalene- adjuvanted flu vaccine (H1N1) immunized group showed the highest significant increase at 120 hours post-stimulation (in which the spleen harvested and stimulated after 21 days of vaccination). These results agree with those of Szyszko et al. (2006) who stated that the expression of type 2 cytokine after the first and the second dose of whole vaccine resulted in clearly elevated expression of IL-10. The peak concentrations were reached at day 25 after one dose of vaccine.

\section{3- Tumor Necrosis Factor (TNF- $\alpha$ ):-}

The cytokines profile in stimulated splenocytes was investigated as TNF- $\alpha$ as markers for the inflammatory response (Szyszko et al., 2006). In the present study the values of TNF- $\alpha$ produced by phytohaemagglutinin (PHA) -stimulated splenocytes of non immunized control group and all the treated groups showed significant increased difference at different intervals (24, 48, 96 and 120 hours post-stimulation). These results are in agreement with those of Carter and Swain (1997) who stated that T lymphocytes were stimulated with PHA increased TNF- $\alpha$ cytokine production after $24 \mathrm{~h}$ post stimulation. PHA was the most potent activator of lymphocytes and monocytes for the production of TNF- $\alpha$ (Jarołsaw et al., 2001).

In the recent study, the elevation of TNF- $\alpha$ values of flu vaccine (H1N1)-stimulated splenocytes of non immunized control group and squalene- non adjuvanted flu vaccine (H1N1) immunized group were observed at different intervals (24, 48, 96 and 120 hours post-stimulation). This result may be due to the action of inactivated virus of vaccine in addition to the effect of thimerosal which plays an essential role in the initiation of allergic condition. This investigation is in agreement with the finding of Migdal et al. (2010) who stated that thimerosal induced dendritic cell (DC) activation, as monitored by overexpression of tumor necrosis factor- $\alpha$. As well as it can stimulate human mast cells to release vascular endothelial growth factor (VEGF), which is also vasoactive and proinflammatory factor (Asadi et al., 2010).

In the present work a higher significant increase of TNF- $\alpha$ produced by flu vaccine (H1N1) -stimulated splenocytes of squalene- adjuvanted flu vaccine (H1N1) immunized group at different intervals $(24,48,96$ and 120 hours poststimulation) were realized at different intervals $(24,48,96$ and 120 hours post-stimulation), these results were accepted by Szyszko et al. (2006) who stated that all the four inflamatory cytokines (GM-CSF, IL-1 $\beta$, IL-6 and TNF- $\alpha$ ) were elevated in vaccinated mice. Generally, the vaccine caused autoimmunity and inflammatory diseases may be due to over immunostimulation and inflammatory action of thimerosal and squalene as adjuvant that demonstrated by high elevation of TNF- $\alpha$ in the current study this suggestion comes in the same line with those of Szyszko et al. (2006) who found that whole vaccine induced high levels of TNF- $\alpha$ cytokines. This is may be due to autoimmunity and inflammatory effect of the vaccine that correlated to many inflammatory diseases that caused by vaccine such as arthritis, granulomatous lesion, atherosclerosis, inflammatory bowel disease (Mukhopadhyay et al., 2012).

\section{The Histopathological and Histochemical Changes:}

In the present study spleen of the suspension- treated (squalene - non adjuvanted vaccine) rats showed many drastic changes in the white pulps. These changes include: increased number of connected white pulps with increased proliferation of lymphocytes, dilated and elongated 
trabecular vein after the first dose of vaccination. These results are in accordance with those of Haggqvist et al. (2005) who found that the thimerosal- treated mice expressed the initial decline in number of splenocytes including $\mathrm{T}$ and $\mathrm{B}$ cells changed to an increase 9 days after onset of the treatment with a strong immunostimulation (Havarinasab et al., 2004) and become more higher again after 30 days of treatment (Havarinasab et al., 2005). The dilated and elongated splenic vein was explained by Khaki et al. (2006) who reported that decreased ribosomes, glycogen granules and cristae of mitochondria may led to corrugated membranes.

Mercury may cause cell proliferation (Nakashima et al., 1994) by pertubating lymphocyte signaling (McCabe et al., 1999) and by attenuating apoptosis of lymphocytes due to interference with the Fas-Fas ligand interaction (McCabe et al., 2003). In the the present study the splenic tissue of suspension treated group after the second dose showed poorly stained B-and T- lymphocytes with numerous haemosidrin granules in the red pulps and some degenerated areas. These changes may be due to the thimerosal activity. These results agree with those of Havarinasab et al. (2005) who concluded that the decrease in spleenocytes may be attributed to injection of thimerosal that caused $65 \%$ reduction in the number of $\mathrm{T}$ - and B-cells in the spleen after many weeks of treatment. In addition, the depletion of lymphocytes may be attributed to apoptosis and necrotic death (Duvall and Wyllie, 1986). Humphrey et al. (2005) noticed that thimerosal caused cytotoxicity by initiation of mitochondrial-mediated apoptosis and cell death as deleterious effects of it. This may explain the appearance of degenerated areas and haemosidrin granules observed in this study in the red pulps under the effect of thimerosal on the cytoskeleton. Nunia et al. (2007) also reported that changed membrane structures of the red blood cell resulted in cell rupture and the leak of hemoglobin and haemosidrin out of the cells. In addition to the toxic effect of thimerosal that include released free oxygen radicals, lipid peroxidation, reactive oxygen species (ROS) and elevated level of nitric oxide (NO) were mentioned by Abdel-Rahman et al. (2013). In such manner they added that lipid peroxidation, mediated by free oxygen radicals, is believed to be an important cause of destruction and damage to cell membranes, this can explain and emphasize presence of degenerated areas and haemosidrin granules in the red pulps of splenic tissue in suspension treated groups as thimerosal effect.

The splenic tissue of adjuvant- treated group (squalene treated group) in the present work after the first dose showed loss of its normal architecture with highly disturbed white pulps, thickened trabeculea, highly dilated and elongated trabecular vein which contained haemolysed RBCs and lots of WBCs, while the second dose showed numerous necrotic areas, highly widened and elongated trabecular vein with ruptured endothelial lining it also contained haemolyzed RBCs and numerous micronuclei. All of these findings may be related to squalene as adjuvant. Adjuvants are foreign to the body and cause adverse reactions (Viera, 2001), they have toxic effect at the molecular level (Anthony, 2009) and cause a morphological changes, including membrane alterations and cell shrinkage (Harold, 2005). The adjuvant of this vaccine contributed to the cascade of reactions called "Gulf War syndrome", documented in the soldiers involved in the Gulf War. Some symptoms included arthritis, anaemia, elevated ESR (erythrocyte sedimentation rate), systemic lupus erythematosus, multiple sclerosis and ALS (amyotrophic lateral sclerosis) (Viera, 2001).

The histopathological alternations that take place in splenic tissue after adjuvant treatment was explained by Nancy et al. (2004) who concluded that the inflammatory response observed in rats with adjuvant-induced arthritis was accompanied by significant biochemical changes of plasma acid phosphatase and membrane-bound neuraminidase activity after adjuvant injection. As well as adjuvant increase vascular permeability that caused local tissue destruction and result in systemic effects that include fever (Harold, 2005). Increased permeability of cell membrane caused osmotic swelling leading to erythrocyte haemolysis (El-Beih et al., 1995). These results declare the inversed haemolysis observed in the present study.

The progressive dilation and congestion of blood sinuses observed in the present study was described by Melamed $e t$ al. (2003) who reported that progressive dilation and congestion of blood sinusoids could be considered as a reactive change that may be related to the inhibitory effect on the vascular smooth muscles which induced relaxation and consequent vasodilatation. This vasodilatation and increased vascular permeability should lead to loss of fluid from the blood which would result in degeneration and necrosis in the tissues and may be considered as a reaction to progressive epithelial cell death and atrophy of the tissue (Danz et al., 1998).

Adjuvant also generate cytotoxic $\mathrm{T}$ lymphocytes which able to lyse target cells (Anthony and Allison, 2002) and cause little tissue reaction as liposomes and immunestimulating complexes (ISCOMs1) (Gomez-Vargas et al,. 2004). As same as cytochrome $\mathrm{c}$ was shown to leak from the mitochondria and cells undergoing both apoptosis and necrosis, so adjuvant mediated cell death as toxic effects (Humphrey et al., 2005).Burk et al. (1995) attributed necrosis to the depletion of glutathione in the tissue, which is one of vaccine effect (Abdel-Rahman et al., 2013).

squalene as adjuvant may also exhibit atherosclerosis in the tissue (Natalie et al., 2001). Vaccine induced glomerular, mesangial and systemic vessel wall immune- complex (IC) deposits and antinuclear antibodies (ANA) (Havarinasab and Hultman, 2006). All of these findings may be attributed to the elongation of trabecular vein with ruptured endothelial lining with occurrence of systemic vessel wall IC deposits and atherosclerosis which mentioned as H1N1 vaccine symptoms and may emphasize the main cause of these changes due to squalene- treatment.

In the present study increased proliferation of the white pulps with highly elongated, branched and thickened wall of the central arteries and highly dilated trabecular vein which contained haemolysed blood cells were observed in the splenic tissue of rats treated with suspension and 
adjuvant (squalene - adjuvanted vaccine) after the first dose. Also, destructed walls of central arteries, bizarre structure and distribution of white pulps, appearance of numerous degenerated areas and pools of degenerated RBCs with numerous haemosidrin granules were noticed after the second dose. All of these results may be due to H1N1 vaccine and its gradients, this suggestion comes in the same line with those of Abdel - Rahman et al. (2013) who found that sections of thiomersal, adjuvant and H1N1 vaccine exposed brains showed vacuolation, degenerated, necrosis and apoptosis of neurons. Whereas, increased lymphocytes and RBCs in the dilated blood sinuses and degenerated areas in the present study were demonstrated also by Moustafa and Hafez (1998), they reported that the haemorrhage in the liver tissue may be related to increased intravascular tension. The internal bleeding may be due to irregular prothrombin activity, they added that the functional changes in homeostasis efficiency probably occur as a result of temporary destructive alternation which they noticed in the tissue.

Results of the present study showed increased stain affinity of collagen fibers in splenic tissue of all the treated groups, especially in the thickened capsule, trabeculea, walls of blood vessels and red \& white pulps, in addition to around the wall of the central arteries in squalene - non adjuvanted vaccine group after the second dose with brightly stained pools of RBCs in squalene - treated group after the second dose. These changes may be due to the detrimental effect on the tissue and endothelium (Natalie et al., 2001).

Horn et al. (1985) declared that the presence of collagen in the presinusoidal spaces might affect the blood supply to cells and would reduce the exchange of metabolites, perhaps causing cellular dysfunction and necrosis. The collagen elevation in squalene and squalene -adjuvanted vaccine treated groups may be due to squalene- related to arthritis that caused by vaccine treatment, this suggestion comes in the same line with those of Kakizoe (1999) who found that arthritis was induced by immunization with intradermally emulsion made with adjuvant. Williams et al. (2012) stated that arthritis is a type of collagen vascular diseases that associated with collagen and blood vessel abnormalities and are autoimmune in nature and it undergo autoimmune connective tissue disorders.

Highly reduced total protein was detected in the splenic tissue with moderately stained capsule of all the treated groups, while, negatively stained degenerated areas and deeply stained haemosidrin granules in the red pulps were observed in suspension treated group after the second dose, in addition to moderately stained trabeculea and walls of the blood vessels in squalene - treated group after the first dose. This protein depletion of squalene- nonadjuvanted vaccin may be due to thimerosal, this finding is in agreement with those of Yee and Choi (1996) who found that mercury treatment caused biochemical damage to tissues and genes through diverse mechanisms, such as disrupting membrane potential, altering protein synthesis and mitochondrial damage. Havarinasab et al. (2004) demonstrated that thimerosal can stimulate human mast cells to release vascular endothelial growth factor (VEGF), which is also vasoactive and proinflammatory. In addition to the thimerosal mediated cell death as deleterious effects, the thimerosal in micromolar concentrations also rapidly induce membrane and DNA damage and initiate caspase-3dependent apoptosis in human neurons and fibroblasts (Baskin et al., 2003). The protein depletion of squalenetreated and squalene- adjuvanted vaccine groups may be due to the ability of adjuvant to induce lysis of target cells by initiation of mitochondrial reaction (Anthony and Allison, 2002), or tissue reaction as liposomes stimulating complexes (Gomez-Vargas et al., 2004). It may also result by tissue destruction as activated vascular permeability and result in systemic effects that include fever and the production of acute-phase proteins (Harold, 2005). In 2007, Eid and Al Dossary stated that decreased protein content in tissue may be due to the drastic effect on the rough endoplasmic reticulum (RER), mitochondria and Golgi apparatus and increased lysosomes in the cells. Meanwhile Gorczynska (1987) and Al Gahtani (2006) reported that vacoulation and degeneration led to decreased protein content in the tissue, but congested blood vessels and haemorrhagic areas showed increased RBCs which was accompanied by increased stain affinity of total protein.

Highly decreased PAS positive materials were detected in splenic tissue of rats of all the treated groups, but highly thickened and deeply stained trabeculea were realized with numerous haemosidrin granules and depleted RBCs and WBCs inside the trabecular vein. Decreased glycogen content observed in the tissue post vaccination may be due to vacuolation and degeneration of the tissue that occurred by thimerosal in squalene- nonadjuvanted vaccine groups or by squalene in djuvant- treated groups and by thimerosal and squalene in squalene- adjuvanted vaccine groups, also this suggestion comes in the same line with those of Abdel -Rahman et al. (2013) who found that sections of thiomersal, adjuvant, antigen and $\mathrm{H} 1 \mathrm{~N} 1$ vaccine exposed brains showed vacuolation and degenerated neurons as well as necrotic and apoptotic neurons in hypothalamus, striatum and cerebral cortex. Decreased polysaccharides content in the degenerated epithelial cells of bronchioles and haemolysed RBCs was detected also by Abu El Naga (1989). She stated that this decrease may be due to decreased T3 and T4 hormones of the thyroid glands, which lessen entrance of glucose to the cells, this investigation and the result of the present study were insured the finding of Viera (2001) who reported that the adjuvant of this vaccine contributed to the cascade of reactions called "Gulf War syndrome", in which antithyroid effects were documented in its symptoms. In this respect Jirtle et al. (1990) recorded that the histological and histochemical changes of congested blood vessels that contained densely stained blood cells may be due to the injury of blood vessels provoking anoxia of tissue with degeneration, vacuolation and necrosis of the tissue. The adjuvant may incorporate carbohydrate moieties or molecular configurations that increase delivery to macrophages and dendritic cells via specific receptors (Bonifaz et al., 2004), also adjuvant act as immunomodulator by recruitment and activation of 
macrophages and dendritic cells which lead to other inflammatory sequelae (Harold, 2005). Increased stain affinity of RBCs inside the blood vessels was discussed by Junqueira and Carneiro (2003) who stated that RBCs contain $10 \%$ carbohydrates of their weights; this may explain increased stain affinity of PAS+ve materials inside the congested sinuses and hemorrhagic areas observed in this study.

\section{References}

Abdel- Rahman, M., Mohamed, A., Essam, N., Abdel - Moneim, A. (2013). Studies on H1N1 vaccine-induced monoamines alternations and oxidative stress on brain of adult mice. J. Appl. Pha. Sci., 3 (04): 48-53.

Abu El Naga (1989): Synergistic effect of nicotine and radiation exposure on the mammalian embryos. M.Sc. Thesis, Faculty of Science, Al Azhar University.

Ahmed, A., Yehia, H. (2007). Diazinon immunotoxicity in mice: modulation of cytokines level and their gene expression. Toxicology, 236: 123-131.

Al Gahtani, S. (2006). Histological and histochemical studies on the effect of two different types of magnetic field on the liver and kidney of albino rats. M.Sc. Thesis, Zoology Department, Girls College of Science, Dammam, K.S.A.

Anshu, A., Poonam, K., Sudhanshu, A., Sastry, G. and Sudhir, G. (2006). Thimerosal and immune Function. Autism Research Review Intrenational, 20 (4): 1-6.

Anshu, A., Poonam, K., Sudhanshu, A., Sastry, G. and Sudhir, G. (2007). Thimerosal induces TH2 responses via influencing cytokine secretion by human dendritic cells (DC). J. Leukocyte Biol., 81(2): 474-482.

Anthony, C. and Allison (2002). Squalane emulsions as adjuvants. Science Direct, 19 (1): 87-93.

Anthony, F (2009). Clinical trials of 2009 H1N1 influenza vaccines in children. National Institute of Allergy and Infectious Diseases (NIAID), 9: 921-931.

Anthony, L., Desbien, J., Reed1, R., Bailor1, Natasha, C., John, L., Mark, O., Christopher, F.,Darrick, C., Steven, G., Reed and Malcolm, D. (2015). Squalene emulsion potentiates the adjuvant activity of the TLR4 agonist, GLA, via inflammatory caspases, IL-18, and IFN- $\gamma$. Europ. J. Immunology, 45(2) : 407-417

Asa, B., Cao, Y. and Garry, F. (2000): Antibodies to squalene in Gulf War Syndrome. Exp. Mol. Pathol., 68(1): 55-64.

Asadi, S., Zhang, B., Weng, Z., Angelidou, A., Kempuraj, D., Alysandratos, D. and Theoharides, C. (2010): Luteolin and thiosalicylate inhibit $\mathrm{HgCl} 2$ and thimerosal-induced VEGF release from human mast cells. Int. J. Immunopathol. Pharmacol., 23(4):1015-1020.

Barbro, C., Asa, J., Anders, L., Anders, B. and Johnny, L. (2000). The endogenous adjuvant squalene can induce a chronic T-cell-mediated arthritis in rats. American Journal of Pathology, 156 (6):2057-2065.

Baskin, S., Ngo, H. and Didenko, V. (2003). Thimerosal induces DNA breaks, caspase-3 activation, membrane damage and cell death in cultured human neurons and fibroblasts. Toxicol. Sci., 74(2): 361-368.

Baudner, C., Ronconi, V., Casini, D., Tortoli, M., Kazzaz, J. and Singh, M. (2009). MF59 emulsion is an effective delivery system for a synthetic TLR4 agonist (E6020). Pharm. Res. 26: 1477-1485.

Bonifaz, C., Bonnyay, P., Charalambous, A., Darguste, I., Fujii, S., Soares, H., Brimnes, K., Moltedo, B., Moran, M., and Steinman, M. (2004). In vivo targeting of antigens to maturing dendritic cells via the DEC-205 receptor improves T cell vaccination. J. Exp. Med., 199: 815-824.

Brouckaert, P. (1993). Tumor necrosis factor, its receptors and the connection with interleukin 1 and interleukin 6. Immunobiology, 187: 317-29.

Burk, R., Hill, K., Awad, J., Morrow, J., Kato, T., Cockell, K. and Lyons, P. (1995). Pathogenesis of diquatinduced liver necrosis in assessment of the role of lipid peroxidation and selenoprotein P. Hepatology, 21: 561-569.

Burton, D. (2003): Mercury in medicine report. Congressional Record, 149:1011-1030.

Carter, L. and Swain, L. (1997): Single cell analysis of cytokine production. Curr. Opin. Immunol., 9: 177-182.

Centers for Disease Control and Prevention (CDC) (2010): H1N1 flu. Clinical and Public Health Guidance. http://www.cdc.gov/ h1n1flu/ casedef.htm.

Chopra, U., Vohra, H., Chhibber, S., Ganguly, K. and Sharma, S. (1997). TH1 pattern of cytokine secretion by splenic cells from pyelonephritic mice after in-vitro stimulation with hsp-65 of Escherichia coli. Med. Microbio., 46(2): 139-144.

Danz, M., Hartmann, A. and Blaszyk, H. (1998). Mitogenic short-term effects on hepatocytes and adrenocorticol cells: phenobarbital and reserpine as compared with carcinogenic and noncarcinogenic fluorene derivatives. Exp. Toxic. Pathol., 50: 416-424.

David, F. and Andrew, P. (2009). What the heck is an adjuvant, anyway?. In: Swine Flu Vaccine. Joseph Brownstein, ABC News Medical Unit.http://abcnews.go.com/Health/SwineFluNews/story?id $=8296948$.

Diaz-Sanchez, D., Noble, A., Staynov, D., Lee, T. and Kemeny, D. (1993). Elimination of IgE regulatory rat CD8+ T cells in vivo differentially modulates interleukin-4 and interferon-gamma but not interleukin- 2 production by splenic T cells. Immunology, 78(4): 513-519.

Dormitzer, R., Galli, G., Castellino, F., Golding, H., Khurana, S., Del Giudice, G. and Rappuoli, R. (2011). Influenza vaccine immunology. Immu. Rev., 239: 167-177.

Drury, R. and Wallington, E. (1980). Carleton's Histological Technique, 4th Ed. Oxford. Univ. Press, New York, Toronto.

Duvall, E. and Wyllie, A. (1986). Death of the cell. Immunol., 7: 115-119.

Eid, F. and Al-Dossary, A. (2007). Ultrastructural, histological and histochemical studies on the effect of electraomagnetic field on the liver of pregnant rats and their fetuses. The Egyptian J. of Hospital Medicine, 28: 273-294.

El Beih, N., Meky, N., Mansour, M. and El- Shamy, E. (1995). Protective effect of L-methionine on blood induced glutathione, glucose-6-phosphate dehydrogenase and some haematological parameters in gamma irradiated albino male rats. Proc. Egypt. Acad., 45: 31- 45.

Everson, C. A. (2005). Quantitative determination of interleukin-10 in rat serum, buffered solution and cell 
culture medium. Am. J. Regul. Intrgr. Comp. Physiol., 289(4): 1054-1063.

Forrest, L., David, H., Raul, C. and Wolfgang, J. (1996). Proliferation assays with human, rabbit, rat, and mouse lymphocytes. In Vitro Cellular \& Developmental Biology - Animal, 32(9):520-523.

Gangurde, H., Gulecha, V., Borkar, V., Mahajan, M., Khandare, R. and Mundada, A. (2011). Swine Influenza A (H1N1 Virus): A pandemic disease. Syst. Rev. Pharm., 2: 110-124.

Gomez-Vargas, A., Rosenthal, K., McDermott, M. and Hortelano, G. (2004). Continuous antigenic stimulation system (CASS) as a new immunization strategy. Vaccine, 22:3902-3910.

Gorczynska, E. (1987). Liver and spleen morphology, ceruloplasmine activity and iron content in serum of guinea pigs exposed to the static magnetic field. J. Hyg. Epidemiol. Micoblol. Immunol., 31: 357-363.

Haggqvist, B., Havarinasab, S., Bjo, E. and Hultman, P. (2005). The immunosuppressive effect of methyl mercury does not preclude development of autoimmunity in genetically susceptible mice. Toxicology, 208: 149-164.

Harold, S. (2005). Adjuvants and antibody production: dispelling the myths associated with Freund's complete and other adjuvants. ILAR Journal, 46(3): 280293.

Havarinasab, S. and Hultman, P, (2006). alteration of the spontaneous systemic autoimmune disease in ( $\mathrm{nzb} \mathrm{x}$ nzw) f1 mice by treatment with thimerosal (ethyl mercury). Toxicol Appl Pharmacol, 214(1):43-54.

Havarinasab, S., Bjorn, E., Ekstrand, J. and Hultman, P. (2007). Dose and $\mathrm{Hg}$ species determine the T-helper cell activation in murine autoimmunity. Toxicology, 229(1-2): 23-32.

Havarinasab, S., Haggqvist, B., Bjorn, E., Pollard, K. and Hultman, P. (2005). Immunosuppressive and autoimmune effects of thimerosal in mice. Toxicol. Appl. Pharmacol., 204:109-121.

Havarinasab, S., Lambertsson, L., Qvarnstrom, J. and Hultman, P. (2004). Dose-response study of thimerosalinduced murine systemic autoimmunity. Toxicol. Appl. Pharmacol., 194:169-179.

Ho, M. (2009a). Cardiovascular risks from swine flu vaccines. Science in Society, 43:1474-1547.

Horn, T., Jung, J. and Christoffersen, P. (1985). Alcoholic liver injury: early changes of the Disse spase in acinar zone. Liver, 6: 301-310.

Huckriede, A., Bungener, L. and Stegmann, T. (2005). The virosome concept for influenza vaccines. Vaccine, 23 (S. 1): 26-38.

Huffstutter, P.J. (2009): Don't call it swine flu, farmers implore. Los Angeles Times, 69: 20-61.

Humphrey, M., Cole, M., Pendergrass, J. and Kiningham, K. (2005). Mitochondrial mediated thimerosalinduced apoptosis in a human neuroblastoma cell line (SKN-SH). Neurotoxicology, 26(3):407-416.

Islam, R. and Rahman, M. (2010). H1N1 flu (Swine Flu): A global perspective.Int. J. Heal., 10 (2): 1-10.

James, S., Slikker, I., Melnyk, S., New, E., Pogribna, M. and Jernigan, S. (2005). Thimerosal neurotoxicity is associated with glutathione depletion: protection with glutathione precursors. Neurotoxicology, 26: 1-8.
Jarołsaw, B., Danuta, K., Mariola, O. and Marek, Z. (2001). Three-color flow cytometry detection of intracellular cytokines in peripheral blood mononuclear cells comparative analysis of phorbol myristate acetateionomycin and phytohemagglutinin stimulation. Clin. Vaccine Immunol., 8 (2): 303-313.

Jeff,R. (2015). Squalene - A History Of Vaccine Development And The Newest Adjuvant. http://12160.info/profiles/blogs/squalene-a-history-ofvaccine

Jirtle, R., Anscher, M. and Alati, T. (1990). Radiation sensitivity of the liver. In: Advances in Radiation Biology. 14th ed., Academic Press, San Diego.

Junqueira, L. and Carneiro, J. (2003). Basic Histology Text and Atlas. 10th ed., The McGraw-Hill Companies,USA.

Kakizoe, E., Li, S., Kobayashi, Y., Nishikori, Y., Dekio, S. and Okunishi, H. (1999). Increases in mast cells and chymase in fibroproliferative paws of collagen-induced arthritic mice. Inflammation Research, 48 (6): 318-324.

Kelder, B. and Rashidbaigi, A. (1986). A Sandwich radioimmunoassay for human IFN- $\gamma$. In: Methods in Enzymology. Vol. 119. S. Pestka, Academic Press, New York, pp: 582-587.

Khaki, A., Tubbs, R., Shoja, M., Rad, J., Khaki, A., Farahani, R., Zarrintan, S. and Nag, T. (2006).The effects of an electromagnetic fields on the boundary tissue of the seminineferous tubules of the rat: A light and transmission electron microscope study. Folia. Morphol., 65(3): 188194.

Kowalczyk, D., Mytar, B. and Zembala, M. (1997). Cytokine production in transient hypogammaglobulinaemia and isolated IgA deficiency. Clin. Immunol., 100:556-562.

Marie-Paule, K. (2009). Pandemic H1N1 press transcript conference with Gregory, Hartl. WHO, Geneva,http://www.who.int/mediacentre/pandemic_h1n1_p resstranscript_2009_09_24.pdf.

Mazia, D., Brewer, P. and Alfert, M. (1953).The cytochemical staining and measurement of protein with mercuric bromophenol blue. Biol. Bull., 104: 57 - 67.

McCabe, J., Whitekus, M. J., Hyun, J., Eckles, K. G., McCollum, G. and Rosenspire, A. J. (2003). Inorganic mercury attenuates CD95-mediated apoptosis by interfering with formation of CD95-mediated apoptosis by interfering with formation of the death inducing signaling complex. Toxicol. Appl. Pharmacol., 190:146-156.

McCabe, J., Santini, R. and Rosenspire, A. (1999). Low and nontoxic levels of ionic mercury interfere with the regulation of cell growth in the WEHI-231 B-cell lymphoma. Scand. J. Immunol., 50:233- 241.

Melamed, R., Bar-Yosef, S., Shakhar, G., Shakhar, K. and Ben-Eliyahu, S. (2003). Suppression of natural killer cell activity and promotion of tumor metastasis by ketamine, thiopental, and halothane, but not by propofol:mediating mechanisms and prophylactic measure. Anesth. Analg., 97: 1331-1339.

Migdal, C., Tailhardat, M., Courtellemont, P., Haftek, M. and Serres, M. (2010). Responsiveness of human monocyte-derived dendritic cells tothimerosal and mercury derivatives. Toxicol. Applied Pharmacology, 246 (1-2):6673. 
Monteiro, J., Harvey, C. and Trinchieri, G. (1998). Role of interleukin-12 in primary influenza virus infection. J. Virol., 72:4825-4831.

Moustafa, N. and Hafez, M. (1998). The possible protective effects of Nigella Sativa on mice fetuses of mothers exposed to $\gamma$-rays. Egypt. J. Histol., 21(2): 235250.

Mukhopadhyay, S., Farver C., Vaszar, L., Dempsey, O., Popper, H., Mani, H., Capelozzi, V., Fukuoka, J., Kerr, K., Zeren, E., Iyer, V., Tanaka, T., Narde, I., Nomikos, A., Gumurdulu, D., Arava, S., Zander, D. and Tazelaar, H. (2012). Causes of pulmonary granulomas: a retrospective study of 500 cases from seven countries. J. Clin. Pathol., 65 (1): 51-57.

Nakashima, I., Pu, Y., Nishizaki, A., Rosila, I., Ma, L., Katano, Y., Ohkusu, K., Rahman, M., Isobe, K. and Hamaguchi, M. (1994). Redox mechanism 7676as alternative to ligand binding for receptor activation delivering disregulated cellular signals. J. Immun., 152: 1064-1071.

Nancy, W. Marchand, Gollamudi, S. Kishore and Raoul, Carubelli (2004). Neuraminidase activity in the blood and liver of arthritic rats. Experimental and Molecular Pathology, 29 (3): 273-280.

Natalie, K., Nobuhiko, K., William, A., Boisvert, L. and Curtiss, K. (2001). Effect of g-irradiation and bone marrow transplantation on atherosclerosis in LDL receptordeficient mice. Arteriosclerosis, Thrombosis and Vascular Biology, 21: 1674-1680.

National Institute of Allergy and Infectious Diseases (NIAID) (2009). Thimerosal in Vaccines.

Szyszko, E., Brokstad, K. Cox, R. J. Hovden, Madhun, A. and Haaheim, L. R. (2006). Impact of influenza vaccine formulation with a detailed analysis of the cytokine response. Scandinavian Journal of Immunology, 64: 467-475.

Trifonov, V., Khiabanian, H. and Rabadan, R. (2009): Geographic dependence, surveillance and origins of the 2009 influenza A (H1N1) virus. New England Journal of Medicine., 61(2): 115-119.

Vetvicka, V. and Vetvickova, J. (2009): Effects of glucan on immunosuppressive actions of mercury. Med. Food, 12 (5):98-104.

Viera, S. (2001). Adverse effects of adjuvants in vaccines. Whale, $8(2)$ : 1-11.

Williams, R., Ma, Y., Ibrahim, F., Walker, D., Hassell, A., Choy, H., Kiely, W., Walsh, A., Young, A., http://www.niaid.nih.gov/topics/vaccines/research/pages/va ccines.aspx.

Nunia, V., Sncheti, G. and Goyal, P. K. (2007). Protection of Swiss albino mice against whole-body gamma irradiation by diltiazem. British Journal of Radiology, 80: 77-84.

Paget, G. E. and Barnes, J. M. (1964). Interspecies dosage conversion scheme in evaluation of results and quantitative application in different species. Evaluation of Drug Activities: Pharmacometric, 1: 160-162.

Pearse, A. (1977). Histochemistry, Theoretical, and Applied. 3th ed., vol. 1. Churchill Livingstone, London.

Picker, J., Singh, K., Zdraveski, Z., Treer, R., Waldro p, L.,Bergstresser, R. and Maino, C.(1995). Direct demonstration of cytokine synthesis heterogeneity among human memory effector $\mathrm{T}$ cellsby flow cytometry. Blood, 86:1408-1419.

Roan, S. (2009). Swine flu debacle of 1976 is recalled. Los Angeles Times (latimes). http://articles.latimes.com/2009/apr/27/science/sci-swinehistory27?pg=2.

Sanfeliu, C., Sebastia, J. and Ki, S. U. (2001).Methylmercury neurotoxicity in cultures of human neurons, astrocytes, neuroblastoma cells. Neurotoxicology, 22: 317-327.

Segal, L., Wouters, S., Morelle, D., Gautier, G., Le Gal, J., Martin, T., Kuper, F., Destexhe, E. and Garçon N. ( 2015). Non-clinical safety and biodistribution of AS03adjuvanted inactivated pandemic influenza vaccines. J. Appl. Toxicol., 10:1002-1015.

Smith, J. (2009). Batch of H1N1 vaccine recalled for severe reactions. Toronto Star, 7(2): 81-86.

Scott, L. and Rheum, J. (2012). Remission in early rheumatoid arthritis. Pred. Treat. Res.,39 (3) :470-475.

World Health Organization (WHO) (2009a). Clinical features of severe cases of pandemic influenza. http://www.who.int/csr/disease/swineflu/notes/h1n1_clinica 1_features_20091016/en/index.html.

World Health Organization (WHO) (2009b). Influenza (Seasonal). http://www.who.int/mediacentre/factsheets/fs211/en/

Yee, S. and Choi, H. (1996). Oxidative stress in neurotoxic effects of methylmercury poisoning. Neurotoxicology, 17: 17-26. 